\title{
An estimation accuracy of state observers under uncertain initial conditions
}

\author{
Lozynskyy A. O. ${ }^{1}$, Demkiv L. I. ${ }^{1}$, Vantsevich V. V. ${ }^{2}$, Borovets T. V. ${ }^{1}$, Gorsich D. J. ${ }^{3}$ \\ ${ }^{1}$ Lviv Polytechnic National University, \\ 12 S. Bandera Str., 79013, Lviv, Ukraine \\ ${ }^{2}$ University of Alabama at Birmingham, Birmingham, AL 35294, U.S.A. \\ ${ }^{3}$ US Army CCDC Ground Vehicle Systems Center, Warren, MI
}

(Received 23 September 2019; Revised 3 October 2019; Accepted 5 October 2019)

\begin{abstract}
A fast convergence speed of an observer helps improve the capability to track the states of a system for an arbitrary divergence between a real and an estimated initial conditions. This property of the observers is significantly useful if a system has fast dynamics and its states change rapidly. Thus, the convergence time is one of the main performance criteria of linear and non-linear state observers.

This article presents a comparative analysis of observers for both linear and nonlinear systems in terms of the time of convergence of the observers. The following observers was chosen for this study: the Kalman filter (KF), extended Kalman filter (EKF), unscented Kalman filter (UKF), particle filter (PF), Luenberger observer (LO), and fuzzy-based Luenberger observer (Fuzzy-LO). The listed observers were studied using a non-linear mathematical model of an open-link locomotion module, which movements were studied in stochastic terrain conditions. The mathematical model was then simplified and simulated as a linear model with the purpose to estimate the efficiency of the linear observers. The Fuzzy-LO with an adaptive gain to the estimation error gives better results than the LO, especially in steady states. The PF with a simple Gaussian distribution provides a lower convergence speed than the KF, EKF, and UKF. To faster the convergence of the PF, a novel approach, $\mathrm{PF}^{*}$, that utilizes mixture probability density function of the distribution of initial particles was introduced in the article.
\end{abstract}

Keywords: estimation algorithms, state observers, state-space model, fuzzy logic, mixture distribution.

2000 MSC: $93 \mathrm{~B} 07$

UDC: 681.516 .4

DOI: $10.23939 / \mathrm{mmc} 2019.02 .320$

\section{Introduction}

Very often, control strategies are designed with an assumption that information about the control object is known. Usually, this information can be provided by sensors. However, there are multiple types of signals that cannot be directly measured at the plant or there is a need in special sensors, which can greatly increase the cost of the entire control system. In such cases, application of observers is justified.

It is well known that observers' efficiency is influenced both by the error between the real and presumed initial conditions of systems. Concurrently, the real-time system requires convergence of the observer states to the original system state in a fixed (defined a priori) time [1]. Thus, convergence time of multiple estimation approaches are investigated and evaluated in this article. Huangfu et al. [2] compares the super-twisting sliding mode observer (STSMO) with the adaptive extended Kalman filter (AEKF); as this study indicated, the STSMO has a faster convergence speed when real values deviates

This study has been supported by a grant of the NATO Science for Peace and Security Programme: MYP SPS G5176 "Agile Tyre Mobility for Severe Terrain Environments." 
from initial states. However, the convergence of the STSMO is provided by the proper tuning procedure after many rounds of experiments. In the article written by Guo and Zhao [3], the convergence of various nonlinear extended state observers is proved for applications in nonlinear systems but these observers are not compared with the widespread classical estimation algorithms.

Insufficient convergence speeds of observers can negatively influence the observation process in real-time applications, including vehicle dynamics and terrain mobility control. At that time, in order to estimate a fast dynamics of tire-terrain interrelation, the observer should have the convergence rate in several times faster than considered plant has [4]. In an article by Bogdanski and Best [5], the $\mathrm{UKF}, \mathrm{EKF}$ and $\mathrm{PF}$ are used for the identification of tire and vehicle parameters; results obtained in the article testify that the PF's convergence is slow, hence, this observer is recommended for simple models and systems. Presently, in the scientific literature there is no common approach to the application of different observes with unknown initial conditions to ground vehicles. This article aims to study this technical problem. The next section briefly describes the estimation algorithms, which were then simulated for the states estimation of an open-link locomotion module. The main outcomes of this article are modification of well-known classical algorithms that increase the convergence rate and reduce computational costs. Firstly, the mixed Gaussian probability function is introduced in particle filter $\mathrm{PF}^{*}$ as initial distribution of particles to increase the convergence rate. The mixture distribution is presented by a mixture probability density function that includes three components which reflect the three more probable system states. Secondly, in contrast to the usual fuzzy-Luenberger observer which combines several linear observers switched by fuzzy logic, it is proposed to reduce computational costs by using one observer with nonlinear system model and observer' gain calculated basing on TakagiSugeno model.

\section{State observers}

State observers are designed using mathematical models of physical plants, and the accuracy to estimate a plant's states significantly depends on the accuracy of its model. Therefore, it is important to build a more detailed mathematical model to adequately describe the plant. However, high fidelity mathematical model may increase the computational time needed to estimate the plant's states. To satisfy requirements for the real-time operation, the model can be linearized and, thus, the computational time can be reduced. Therefore, the applicability of various observers for both linear and nonlinear models is also studied in this article.

\subsection{State observers for linear plant model}

Kalman filter. The Kalman Filter (KF) is one of the most widespread techniques to estimate and identify unknown parameters that has been in use since 1960 [6]. The KF allows for estimating an unmeasured state vector with a process noise by using a plant model and measuring available signals that may contain the measurement noise. The diagram of the KF algorithm is given in Fig. 1a. The basic element of the algorithm is the Kalman feedback gain, $K_{k}$, which determines a more trustable data: either the propagation or the measurement data. If the value of the Kalman gain is high, the observer relies on the measurements. Otherwise, the observer relies on the propagation data that come from the model.

Luenberger observer. The Luenberger observer was introduced in 1964 [7] for the state estimation of linear systems. The LO algorithm can be described by a diagram in Fig. $1 b$. Here, $L_{k}$ is the observer gain that should be chosen in a way to minimize the observation error, $e_{k}$, which is the error between the real system states and the estimated states. In order to satisfy the minimization of $e_{k}$ at least in a steady state, the $L_{k}$ should be determined with a condition that the real parts of the eigenvalues of $\left(A_{k}-L_{k} C_{k}\right)$ are negative. For this purpose, the pole-placement method can be used.

Mathematical Modeling and Computing, Vol. 6, No. 2, pp. 320-332 (2019) 


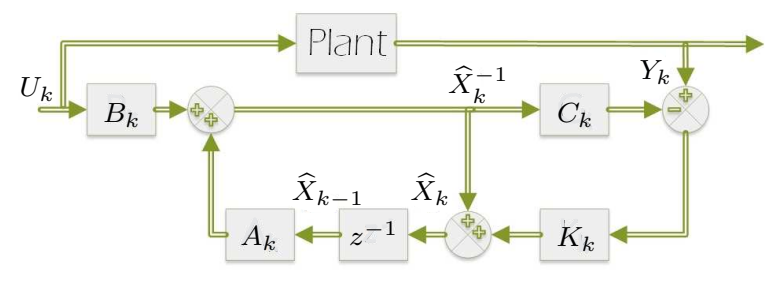

$a$

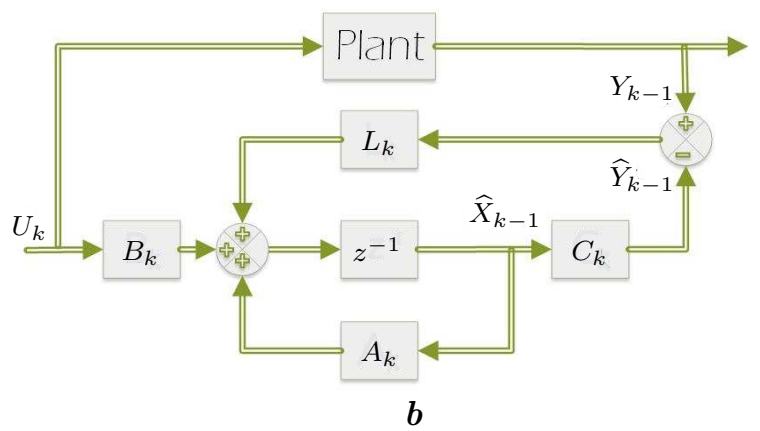

Fig. 1. Diagram of $(\boldsymbol{a})$ a discrete linear Kalman filter, $(\boldsymbol{b})$ a discrete linear Luenberger observer $\left(z^{-1}\right.$ is a time delay). Here $X_{k-1}$ is the state vector, $A_{k}$ is the value of the system matrix at time $t_{k}, B_{k}$ is the value of the input matrix, $U_{k}$ is the vector of inputs, $Y_{k}$ is the vector of outputs, $C_{k}$ is the value of the measurement matrix.

A fuzzy-Luenberger observer for linear systems. The traditional LO utilizes one gain $L_{k}$ that should converge the estimation error to zero. The error convergence speed can be made faster by tuning $L_{k}$ to its higher value. However, it makes the observer more sensitive to various noises. Thus, the main idea of a fuzzy-Luenberger approach is to design an observer with several observer matrices, which are tuned on different dynamics of the estimation error. The gains are combined in the algorithm depending on the error, which is the difference between the estimated output, $\hat{Y}_{k}$, and the measurements, $Y_{k}$. For practicality of such tuning, the error range can be divided into many sub-regions with the membership functions that define instant error values in each sub-regions. However, a large amount of sub-regions complicates the algorithm and cannot really improve its accuracy. In this study, three membership functions were used (see Fig. 2). Thus, the error can be characterised as 'Small', 'Medium', and 'Large'.

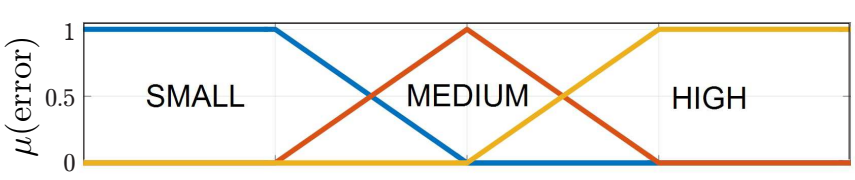

Fig. 2. The membership functions.

When the error is 'Small', the observer gain takes small values to make the observer more robust to noises and to avoid the instability at the state mode. The observers gain values increase as the error value changes from 'Medium' to 'Small'. When the output error of the system is 'Large,' and values of the Luenberger matrix are high, the output of the observer may diverge from real data. To avoid such divergence and reduce the output error of the system's signal, the value of the matrix $L_{k}$ is lowered as compared to its value in the case of the 'Medium' error. The fuzzy-LO works according to the diagram of the LO (see Fig. 1b), but in contrast to LO, the fuzzy-LO gain is calculated as the Takagi-Sugeno (T-S) Fuzzy Model output:

$$
L_{k}=\frac{v_{1} L_{s, m, h}+v_{2} L_{s, m, h}+\ldots+v_{N} L_{s, m, h}}{\sum_{j} v_{j}} .
$$

Here, $v_{j}$ is the membership function for the fuzzy set of the $j$-rule, $j=1,2, \ldots, N, N$ is a number of the rules $N=M^{2}, M$ is the number of measurements (i.e., sensors); $L_{s, m, h}$ is the observer gain denoted as $s, m, h$ for each sub-regions. In a case of a single measurement, the value of $v_{j}$ is equal to the membership function, $\mu_{i}$.

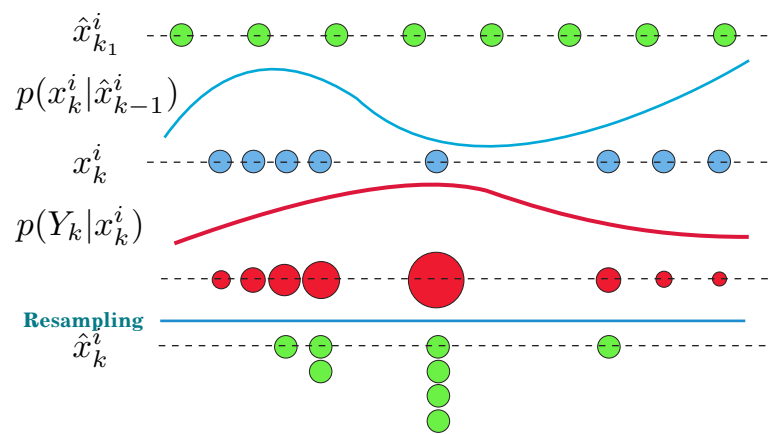

Fig. 3. Visualisation of the Particle Filter algorithm.
Particle filter. The Particle Filter (PF) is one of the Monte-Carlo sequential methods that was introduced by Gordon et al. [8] as a Bayesian bootstrap filter for nonlinear and non-Gaussian systems. The filter is easily adopted to linear system as well. This technique can be applied to Markov system models, which rely on the Bayes rule, i.e., the estimation problem is considered as search for a probability density function that can be approximated by a large number of weighted particles. 
A graphical representation of the Particle Filter algorithm is shown in Fig. 3. Here, the first line from the top consists of an initial set of particles distributed according to the initial probability density function. The second set of the particles is determined by distributing the initial set through the plant model, which can be described by a chosen probability density function $p\left(x_{k}^{j} \mid \hat{x}_{k-1}^{j}\right)$. The next step is to weigh the particles in accordance with the probability density function of the measurement distribution, $p\left(Y_{k} \mid x_{k}^{j}\right)$. The last line in Fig. 3 includes a new generation of the particles, $\hat{x}_{k}^{j}$, obtained after applying a resampling algorithm, which duplicates particles with higher weights.

\section{Particle filter with a mixture distribution model.}

The initial set of the particles is commonly distributed according to the Gaussian distribution. In this article, it is proposed to choose a mixture probability density for initial distribution as shown in Fig. 4. The results for the PF with this initial mixture distribution are denoted as the $\mathrm{PF}^{*}$. The mixture distribution consists of three components with the three means and variations which are chosen to represent the three most likely points in which the

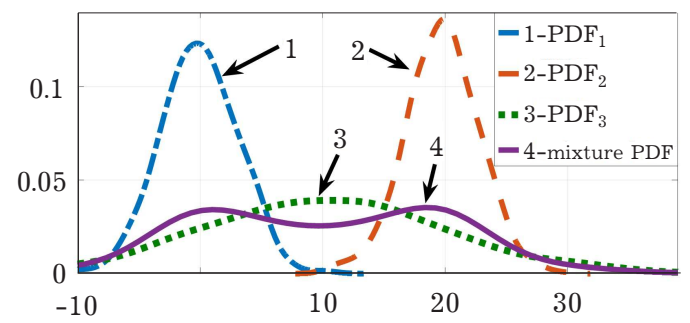

Fig. 4. Diagram of the probability density functions (PDF) for the initial particles distribution, which build mixture probability density function. system states can be: minimal values, maximum values and difference between maximum and minimum values of the system states.

\subsection{State observers for a non-linear plant model}

Extended Kalman filter and Unscented Kalman filter. The traditional algorithm of the KF was modified to make it applicable to nonlinear plant models. The main idea behind the EKF and the UKF filters is similar to the KF. For the gain calculation, different linearization techniques are usually used. In the EKF applications, nonlinear models are linearized by using the Taylor series. In order to overcome the EKF drawback related to Jacobian matrix calculation, which requires the differentiability of the nonlinear system and can cause a substantial estimation error due to the linearization of the system, the UKF was proposed by Julier et al. [9] using an unscented transformation to approximate a nonlinear system. The unscented transformation is a numerical high-order approximation technique that approximates nonlinearities using a minimal set of deterministically selected sample points known as sigma-points.

A fuzzy-Luenberger observer for non-linear models. For a nonlinear system, the extended LO can be designed, however, this observer requires to calculate Lie derivatives, which complicates the algorithm. Therefore, in order to avoid the calculation of Lie derivatives, the Fuzzy-Luenberger observer was proposed for nonlinear systems. This observer combines several linear LOs, which are synthesized at certain points of the linearized nonlinear system by Taylor series; a fuzzy logic switcher selects between the LOs depending on the location of the states. The fuzzification is based on the states or the inputs, which are components of nonlinearity factors. Unlike the conventional fuzzy-LO, in this article, it is proposed to calculate only an observer gain using fuzzy logic. Thus, the observer equations can be simplified and written down as follows

$$
\begin{aligned}
\hat{X}_{k} & =f\left(\hat{X}_{k-1}, U_{k}\right)+L_{k}\left(Y_{k-1}-\hat{Y}_{k-1}\right) \\
\hat{Y}_{k} & =h\left(\hat{X}_{k}, U_{k}\right) \\
L_{k} & =\frac{\beta_{1} L_{1}+\beta_{2} L_{2}+\ldots+\beta_{K} L_{K}}{\sum_{l} \beta_{l}}
\end{aligned}
$$

here, $\beta_{l}$ is the membership function for the fuzzy set of $l$ rule, $l=1,2, \ldots, K$ and $K$ is the number of rules $K=S, S$ is the number of the linearized models; $L_{l}$ is the observer gain for the $l$-th linear model. 
In case of a single fuzzy input (input that determines in which region of the linear model the states are located), the $\beta_{l}$ is equal to the membership function $\mu_{i}$. Gain $L_{l}$ for $l$-th linear model is defined by (2) similar to the Fuzzy-Luenberger linear observer.

Particle filter for nonlinear models. The $\mathrm{PF}$ and $\mathrm{PF}^{*}$ for a non-linear model is the same as for a linear model, however the probability density functions of states and measurements distributions are selected based on a nonlinear behaviour of the system.

\section{Technical application}

In order to compare the above-considered observers, a mathematical model of an open-link locomotion module of an off-road vehicle is introduced below. Fig. 5 shows a layout of the module that comprises several vehicle sub-systems to build one corner of the vehicle. In this study, only normal and longitudinal dynamics of the module is analysed; steering and curvilinear movements are out of the scope of this article. The results presented in this article will be also valid for application other than the one considered as an example in this article.

\subsection{Mathematical model of plant under investigation}

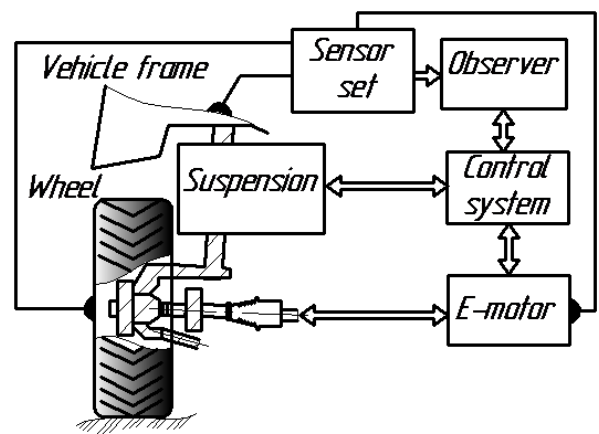

Fig. 5. Diagram of the open-link locomotion module.
The driveline of the module includes a DC electric motor and a reduction gear set that transmits rotational motion from the motor to the wheel (Fig. 5). The mechanical components of the driveline are dynamically elastic and, thus, the rotational dynamics of the driveline should include elastic and damping properties of its mechanical components; an equivalent twomass rotational system is considered in this study for this purpose [10]. The system includes the mass of the wheel with the rotational inertia of $J_{w}$ and an equivalent inertia $J_{e q}$ that comprises the rotational mass of the motor rotor and, in addition, the rotational mass of the gear set and connecting shafts, which are reduced to the shaft of the rotor. The elastic and damping properties of the shafts are described by the equivalent torsional stiffness, $k_{e q}$, and the equivalent torsional damping, $c_{e q}$, that are computed by reducing the stiffness and damping of the gears and shafts to the rotor shaft using the velocity ratio $i$. The rotational dynamics can be written in a state space form as follow [11]:

$$
\left\{\begin{aligned}
\frac{d i_{m}}{d t} & =\frac{1}{L_{a}}\left(\frac{u k_{b a t}}{u_{\max }}-R_{a} i_{m}-k_{e m f} \omega_{m}\right) \\
\frac{d \omega_{m}}{d t} & =\frac{1}{J_{e q}}\left[k_{t} i_{m}-T_{s}-c_{e q}\left(\omega_{m}-i \omega_{w}\right)-T_{f m}\right] \\
\frac{d T_{s}}{d t} & =k_{e q}\left(\omega_{m}-i \omega_{w}\right), \\
\frac{d \omega_{w}}{d t} & =\frac{1}{J_{w}}\left[i T_{s}+i c_{e q}\left(\omega_{m}-i \omega_{w}\right)-T_{w l}-T_{f w}\right] .
\end{aligned}\right.
$$

Here, the state vector $X_{1}$ includes the electric current, $i_{m}$, the angular velocity of the e-motor, $\omega_{m}$ the internal elastic-damping torque, $T_{s}$, the angular velocity of the wheel, $\omega_{w}$; the input vector $U_{c 1}$ includes only one element of the control voltage $u$; the vector of disturbances includes the load torque $T_{w l}$. Additionally, the model is characterized by the following parameters: the armature electric resistance, $R_{a}$, the armature inductance, $L_{a}$, the e-motor constant, $k_{t}$, the back EMF constant, $k_{e m f}$, the maximum voltage output of the Pulse Width Modulation battery, $k_{b a t}$, and the maximum control voltage, $u_{\max }$. 
Nonlinear mechanical friction torque $T_{f m}$, which sufficient influence on e-motor dynamics is considered in $[12,13]$, is always present in the e-motor and gear bearings and a mechanical friction torque $T_{f w}$ in the wheel bearings:

$$
\begin{aligned}
& T_{f m}=\alpha_{0 m} \operatorname{sign}\left(\omega_{m}\right)+\alpha_{1 m} \exp \left(-\alpha_{2 m}\left|\omega_{m}\right|\right) \operatorname{sign}\left(\omega_{m}\right), \\
& T_{f w}=\alpha_{0 w} \operatorname{sign}\left(\omega_{w}\right)+\alpha_{1 w} \exp \left(-\alpha_{2 w}\left|\omega_{w}\right|\right) \operatorname{sign}\left(\omega_{w}\right) .
\end{aligned}
$$

The normal dynamics of the locomotion module is based on the sprung-unsprung mass model

$$
\left\{\begin{aligned}
\frac{d R_{z}}{d t} & =-W_{w} \theta_{n} \sin \theta_{n}+k_{t g}\left(\dot{z}_{r}-\dot{z}_{u}\right)+c_{t g}\left(\ddot{z}_{r}-\ddot{z}_{u}\right), \\
\ddot{z}_{s} & =\frac{k_{s}}{m_{s}}\left(z_{u}-z_{s}\right)+\frac{c_{s}}{m_{s}}\left(\dot{z}_{u}-\dot{z}_{s}\right), \\
\ddot{z}_{u} & =\frac{k_{t g}}{m_{u}}\left(z_{r}-z_{u}\right)+\frac{c_{t g}}{m_{u}}\left(\dot{z}_{r}-\dot{z}_{u}\right)-\frac{k_{s}}{m_{u}}\left(z_{u}-z_{s}\right)-\frac{c_{s}}{m_{u}}\left(\dot{z}_{u}-\dot{z}_{s}\right) .
\end{aligned}\right.
$$

Here, $R_{z}$ is the tire dynamic normal reaction $\theta_{n}$ is the slope of the surface of motion, $W_{w}$ is the static load on the wheel caused by the sprung mass and the unsprung mass, $k_{t g}$ is the tire-soil normal stiffness, $c_{t g}$ is the tire-soil damping factor, $z_{s}$ and $z_{u}$ are the displacements of the sprung and unsprung masses, $m_{s}$ and $m_{u} ; z_{r}$ is the height of the terrain profile, $k_{s}$ and $c_{s}$ are the reduced stiffness and damping of the suspension respectively. The tire dynamic normal reaction and the elastic torque are core variables in the wheel mobility assessment. Thus, the observers designed in this article use the mathematical model given by (3)-(6).

The linear model of the module can be obtained from (3)-(6) by neglecting the nonlinear mechanical friction torques in (3) and linearizing (6) around the steady state. Using the Euler discretized equation, the state-space model was transformed in a discrete form that was run in computer simulations.

\subsection{Design of observers}

An observer of the tire normal reaction and an elastic torque observer were designed by combining the two observers in a cascade scheme that was integrated with the mathematical model of the locomotion module (illustrated in Fig. 6). The proposed cascade-based approach makes the tuning procedure of the observers simple and, thus, the observability problem can be omitted.

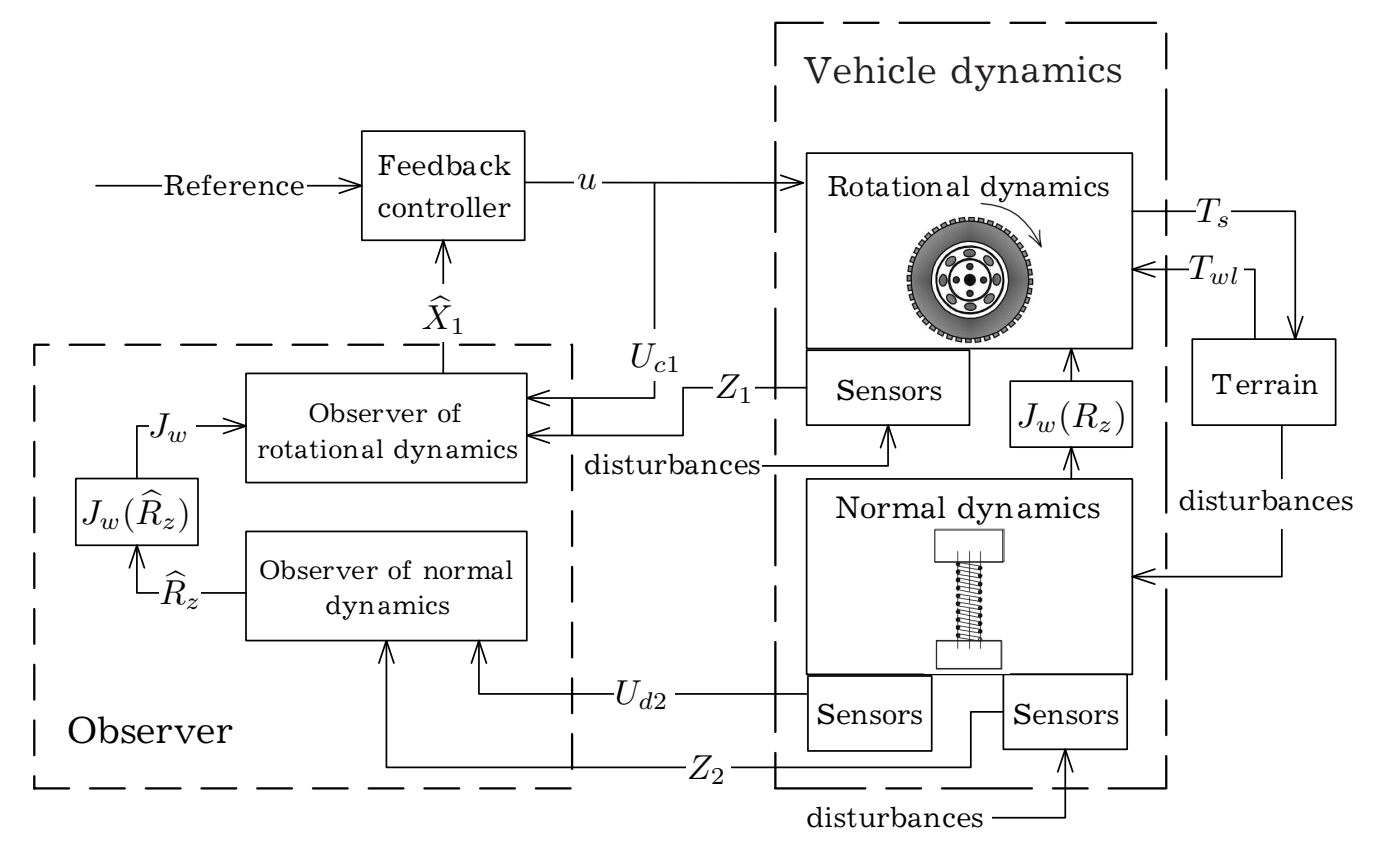

Fig. 6. Diagram of the locomotion module model with the feedback controller and the observer model. 
The rotational and normal dynamics of the locomotion module are coupled due to the impact of the tire normal reaction on the tire rolling resistance and the traction force. Moreover, the wheel rotational inertia varies due to the changes of the tire rolling radius caused by dynamic changes of the tire normal reaction. The feedback controller in Fig. 6 was designed by using the pole placement method to satisfy a reference velocity profile of the locomotion module [10].

For the observer design, the following state vectors, inputs, outputs and variables, which are measured by virtual sensors, are further introduced using a state-space representation form as follows

$$
\begin{gathered}
\hat{X}_{1}=\left[i_{m}, \omega_{m}, T_{s}, \omega_{w}\right]^{\mathrm{T}}, \\
\hat{X}_{2}=\left[z_{s}, \dot{z}_{s}, z_{u}, \dot{z}_{u}, R_{z}\right]^{\mathrm{T}}, \\
U_{c 1}=[u], \quad U_{d 2}=\left[z_{r}, \ddot{z}_{r}, \ddot{z}_{u}, \theta_{n}, \dot{\theta}_{n}\right], \\
Z_{1}=\left[i_{m}, \omega_{w}\right]^{\mathrm{T}}, \quad Z_{2}=z_{r} .
\end{gathered}
$$

It is assumed that the virtual sensors to measure the components of the vectors, $Z_{1}, Z_{2}$, have the ideal transfer functions of unity. According to the chosen sensor signals in (9) and the vectors of the estimated states in (7), the observation models $\hat{Y}_{1}$ and $\hat{Y}_{2}$ (see Fig. 6) can be written as follows:

$$
\left\{\begin{array}{l}
\hat{Y}_{1}=h_{1}\left(\hat{X}_{1}\right)=\left[\begin{array}{ll}
i_{m} & \omega_{w}
\end{array}\right]^{\mathrm{T}}, \\
\hat{Y}_{2}=h_{2}\left(\hat{X}_{2}, U_{2}\right)=\frac{1}{k_{t g}}\left(R_{z}-W_{w} \cos \theta_{n}+k_{t g} z_{u}-c_{t g}\left(\dot{z}_{r}-\dot{z}_{u}\right)\right) .
\end{array}\right.
$$

A white Gaussian noise was utilized in this study to model other possible disturbances, which cannot be included in the mathematical model of the module due to their unknown nature but can influence dynamics of the module and signals of the sensors. It is should be noted that any preceding filter for sensor signals was not used.

\subsection{Tuning of observers}

Load torque $T_{w l}$ is an unknown stochastic disturbance that influences the rotational dynamics as shown in Fig. 6. For the KF, EKF and UKF tuning, the influence of the stochastic load torque on the wheel angular velocity is taken into account by the diagonal element in the process noise covariance matrix, which introduces the wheel velocity variation. The diagonal element is tuned by assigning a higher value than the values of other elements of the matrix. The initial conditions of the posterior covariance matrix are assigned as high values to increase the degree of the convergence of estimate states to real states.

The number of particles of the PF should be selected in a way that allows for decreasing the computational time, but keeping up an appropriate estimation accuracy. Based on analysis that was made in previous paper [11], the number of particles of the PF that satisfies to such requirements is accepted as 250. The resampling method from [14] was used for replacing one set of particles and their weights with another set.

The Luenberger observer was tuned using the pole-placement method to make the observer response faster than the response of the closed-loop system in order to reduce the effect of the observer on the system behaviour. The fuzzy-Luenberger observer for the linear model was tuned similarly to the conventional LO considering the points mentioned in Section 2.1. The fuzzy-Luenberger observer for the nonlinear model was tuned according to the recommendations given in Section 2.1 and 2.2. The fuzzifer inputs are the rotational speeds of the wheel and the motor. The Luenberger observers were tuned in case of continuos model. The observers were discretised by using the Euler discretized equation. 


\section{Results and discussions}

In order to compare the efficiency of the observation algorithms the time of convergence was studied under different values of the initial divergence of estimated states. The convergence time was defined as the time that is required for the observer to reach $5 \%$ estimation error zone and remain there. The initial divergence of estimated state, $\delta$, was defined as a percentage of a possible maximum value of the state; thus, the initial divergence ranged from zero to 100\%. Fig. 7 through 12 illustrate computational results of the above-selected criteria to estimate the designed observers. Additionally, Fig. 13 show the influence of the observers' outputs on the system output (i.e., the wheel velocity).

\subsection{State observers for linear model}

The compassion between the $\mathrm{PF}^{*}$ with the initial mixture probability density function and the $\mathrm{PF}$ with an initial Gaussian distribution of particles is given in Fig. 7. The PF* shows a faster convergence rate in contrast to $\mathrm{PF}$. Thus, the $\mathrm{PF}^{*}$ will be considered herein.

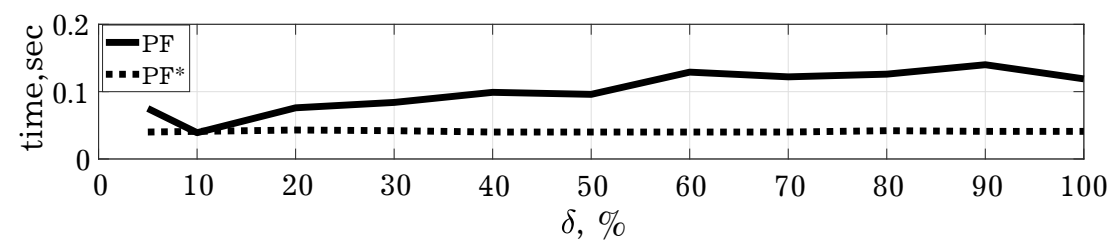

a

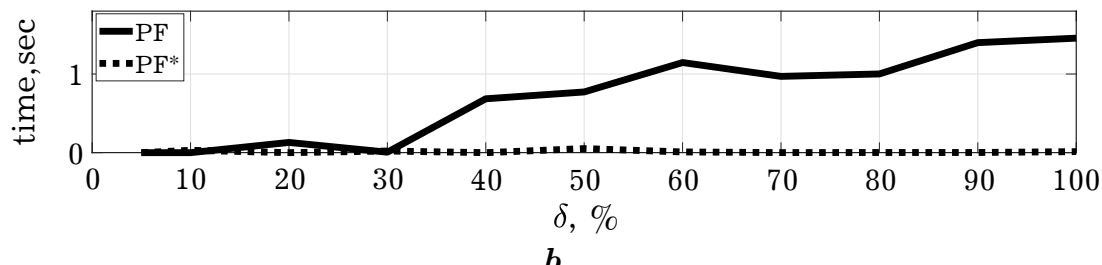

Fig. 7. The time of a convergence of $(\boldsymbol{a})$ estimated elastic torque and $(\boldsymbol{b})$ estimated normal reaction by the $\mathrm{PF}$ with Gaussian initial distribution and the $\mathrm{PF}^{*}$ with the mixture probability density function to $5 \%$ estimation error zone.

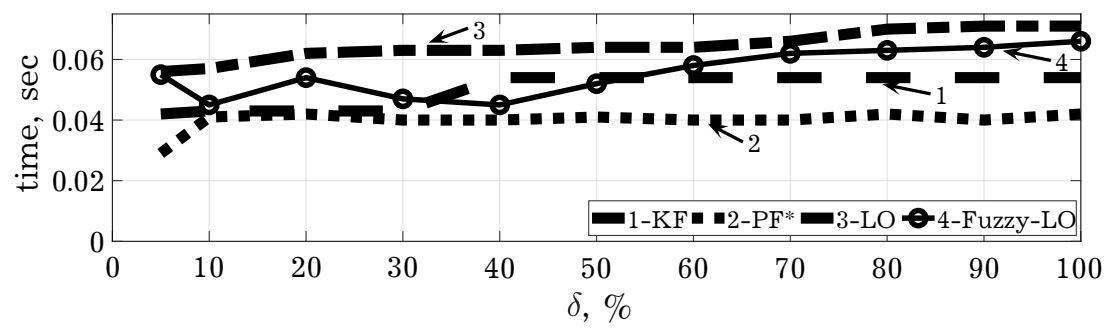

$\boldsymbol{a}$

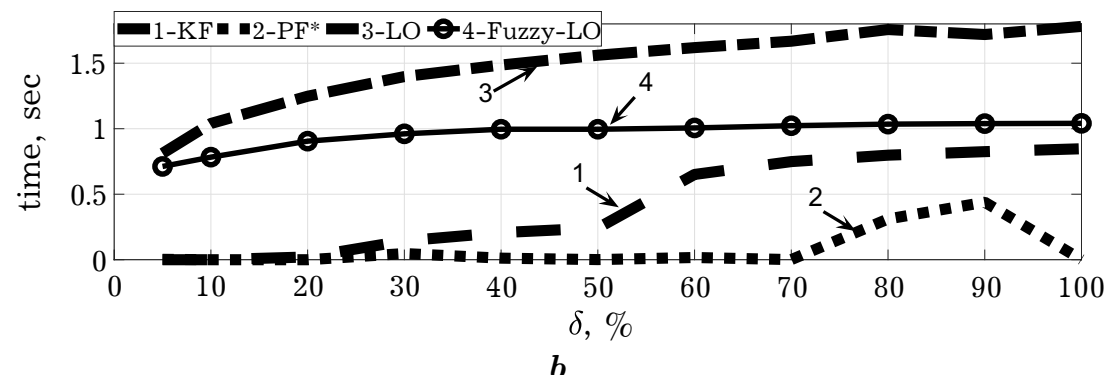

Fig. 8. The time of convergence of $(\boldsymbol{a})$ elastic torque and $(\boldsymbol{b})$ normal reaction estimated by linear observers to the zone of five-percentage error. 
The convergence time of the observers for the linear model of the module is given in the Fig. 8. It can be concluded that the observers provide different values of the time convergence to observe the elastic torque and the tire normal reaction. As seen, the $\mathrm{PF}^{*}$ with the mixture probability density function gives the best convergence results. The KF gives a slightly lower convergence rate than the $\mathrm{PF}^{*}$ but it is still faster than the LO and the fuzzy-LO. The fuzzy-LO provide a smaller convergence time as compared to the $\mathrm{KF}$ at the initial divergence of $40 \%$. However, in case of the normal reaction estimation, the fuzzy-LO does not show such gainful behavior (see Fig. $8 b$ ) because the tuning of the membership functions of the two observers, which are combined in the cascade scheme, is different. In another words, the different tuning of the membership functions, different defuzzification algorithms and fuzzy rule set can provides different convergence rate of the observer. This tuning procedure is out of the scope of this paper. The fuzzy logic was tuned to get as possible good results after short tuning procedure using a trial-error method.

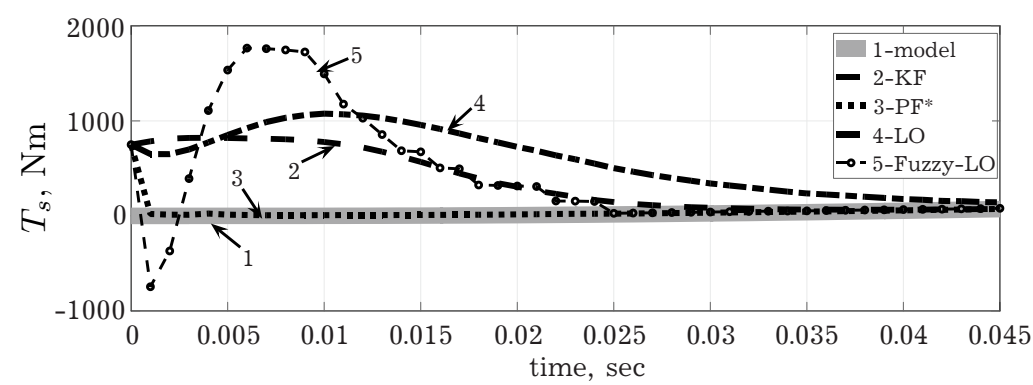

$a$

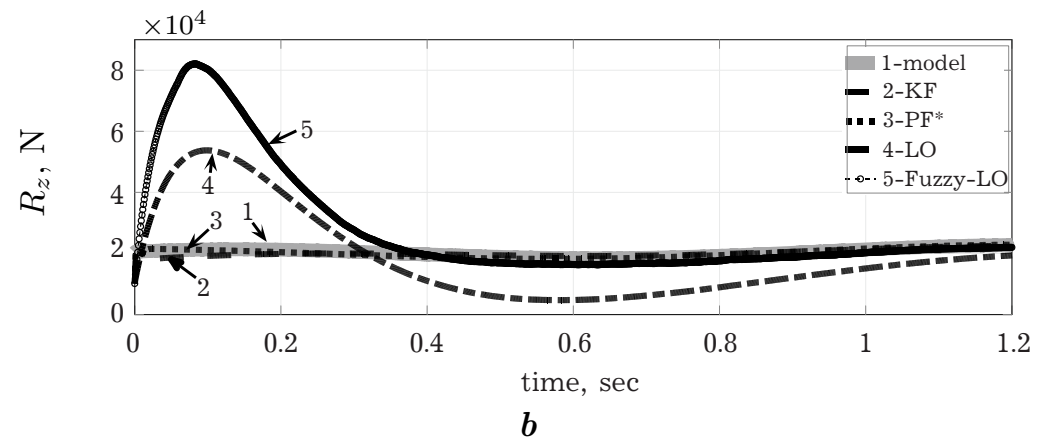

Fig. 9. Estimation of $(\boldsymbol{a})$ elastic torque and $(\boldsymbol{b})$ normal reaction by the linear observers.

Fig. 9 presents the estimation results of the elastic torque and the tire normal reaction in the time domain. As is seen, the $\mathrm{PF}^{*}$ gives the fastest convergence to the actual values. The deviation from the actual values that are seen for fuzzy-LO in Fig. 9 is not much bigger than the deviation computed for the conventional LO. Such dynamics of the fuzzy-LO comes from the properties of fuzzy logics. For example, Fig. $10 a$ presents the fuzzy-LO estimation dynamics obtained by combining dynamics of separate classical LOs with three different gains. The proposed fuzzy-LO gives a better convergence time and a lower estimation error in steady states than the classical LO as seen from Fig. 10b, which presents the estimation error for the elastic torque.

\subsection{State observers for non-linear model}

Fig. 11 to Fig. 12 represent the results of states estimation for the nonlinear model of the open-link locomotion module. The EKF and the UKF give similar results for the estimation of both elastic torque and normal reaction. The $\mathrm{PF}^{*}$ shows the best results at all values of initial divergences. The LO has less convergence in contrast to others. The disadvantage of fuzzy-LO is a big instant divergence of the estimated value from the actual value as shown in Figs. $12 a, 12 b$.

Comparing the results for the linear and nonlinear models, it can be concluded that the three observers that are based on the Kalman filter have had the same convergence properties when the 


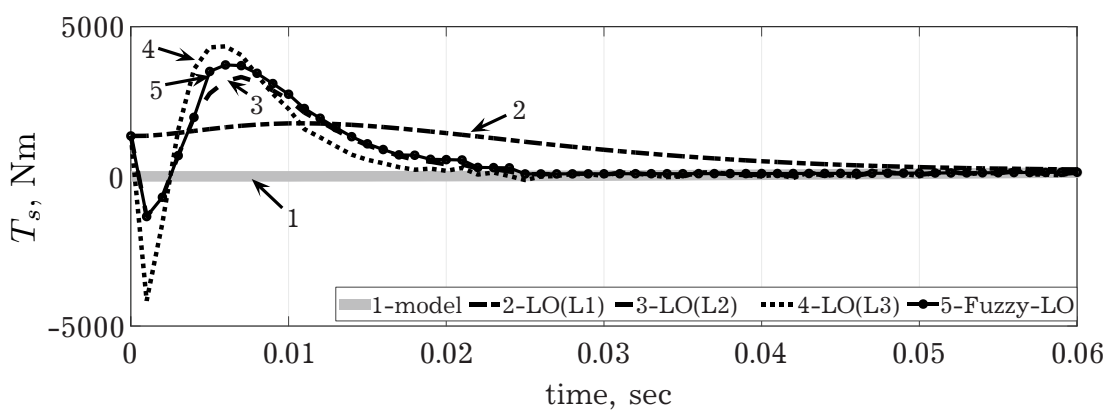

$a$

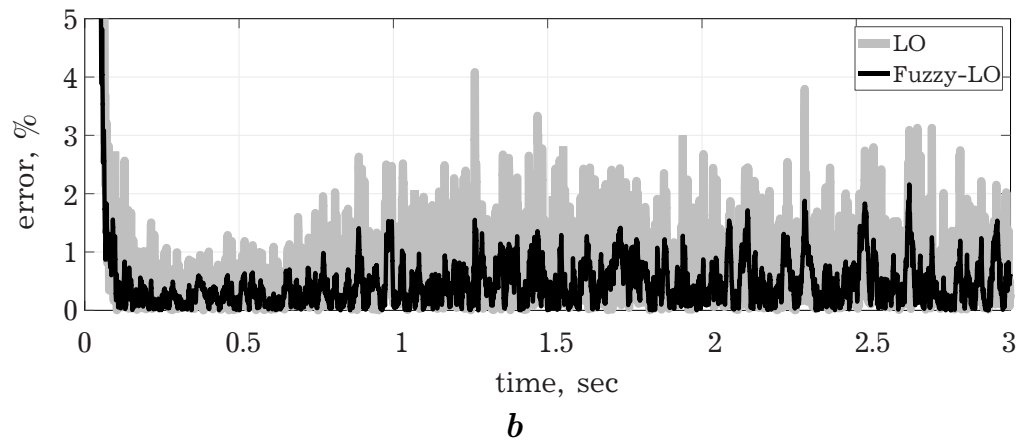

Fig. 10. (a) Estimation error for the Luenberger observer and Fuzzy-Luenberger observer; (b) Estimated normal reaction by LOs and Fuzzy-LO.

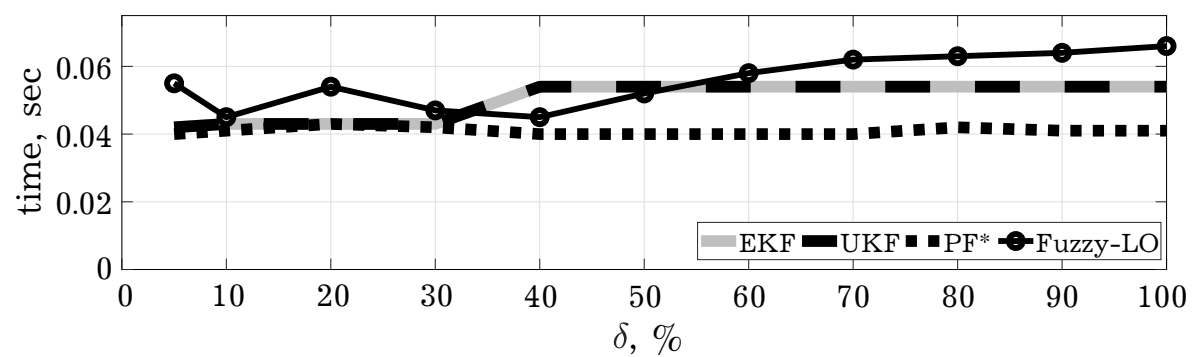

$a$

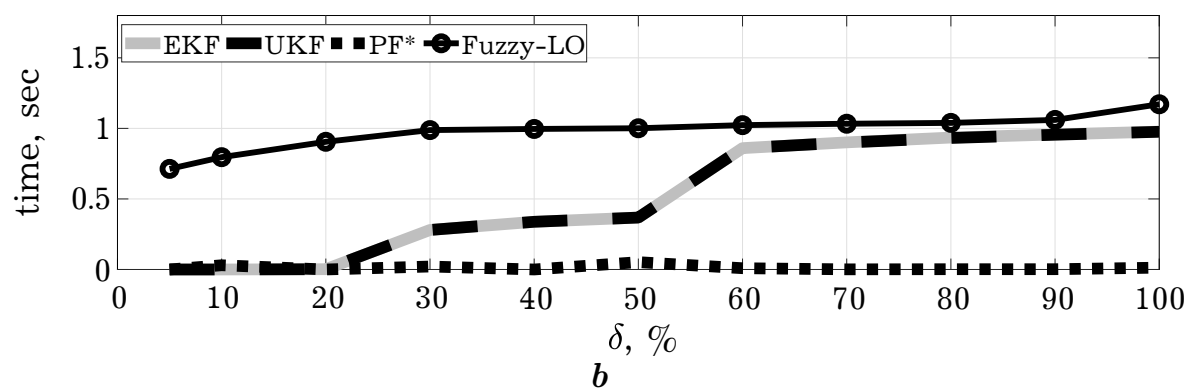

Fig. 11. The time of convergence of $(\boldsymbol{a})$ elastic torque and $(\boldsymbol{b})$ normal reaction estimated by the non-linear observers to the zone of the $5 \%$ error.

initial state differs from the real state. The $\mathrm{PF}^{*}$ gives the best results for both the linear and nonlinear models. For closed-loop systems, the speed of the convergence influences the dynamics of the system outputs, as shown in Fig. 13. By comparing data in Fig. 13 with the results in Fig. 7 and Fig. 11, it becomes obvious that the faster the convergence of the estimated value of the elastic torque, the faster the system output returns to the desired dynamics. The desired dynamics of the system is the dynamics that should be provided by the full state feedback controller when all system states are measured by sensors. It is worth noting that the fuzzy-LO leads to a worse dynamics of the controlled output than the other observers as in shown in Fig. 13. 

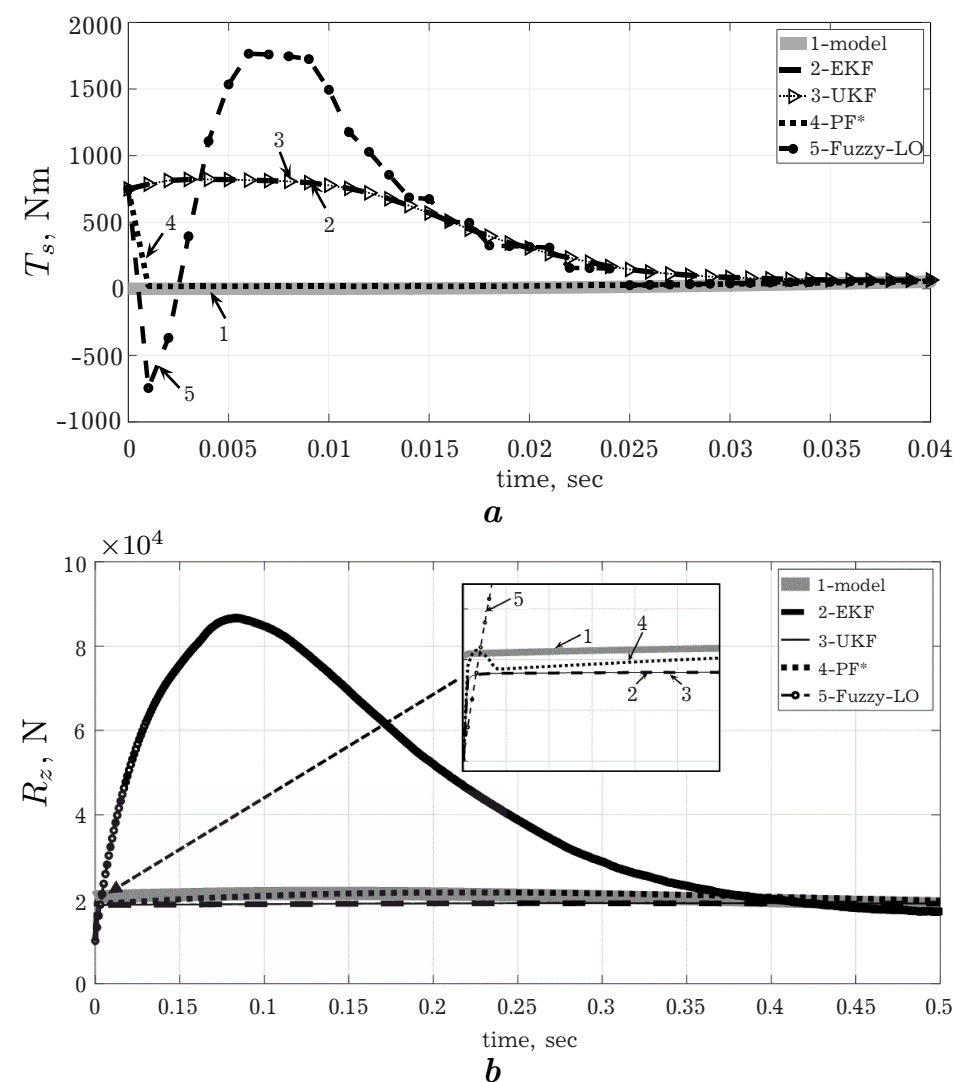

Fig. 12. Estimation of $(\boldsymbol{a})$ elastic torque and $(\boldsymbol{b})$ normal reaction by the non-linear observers.
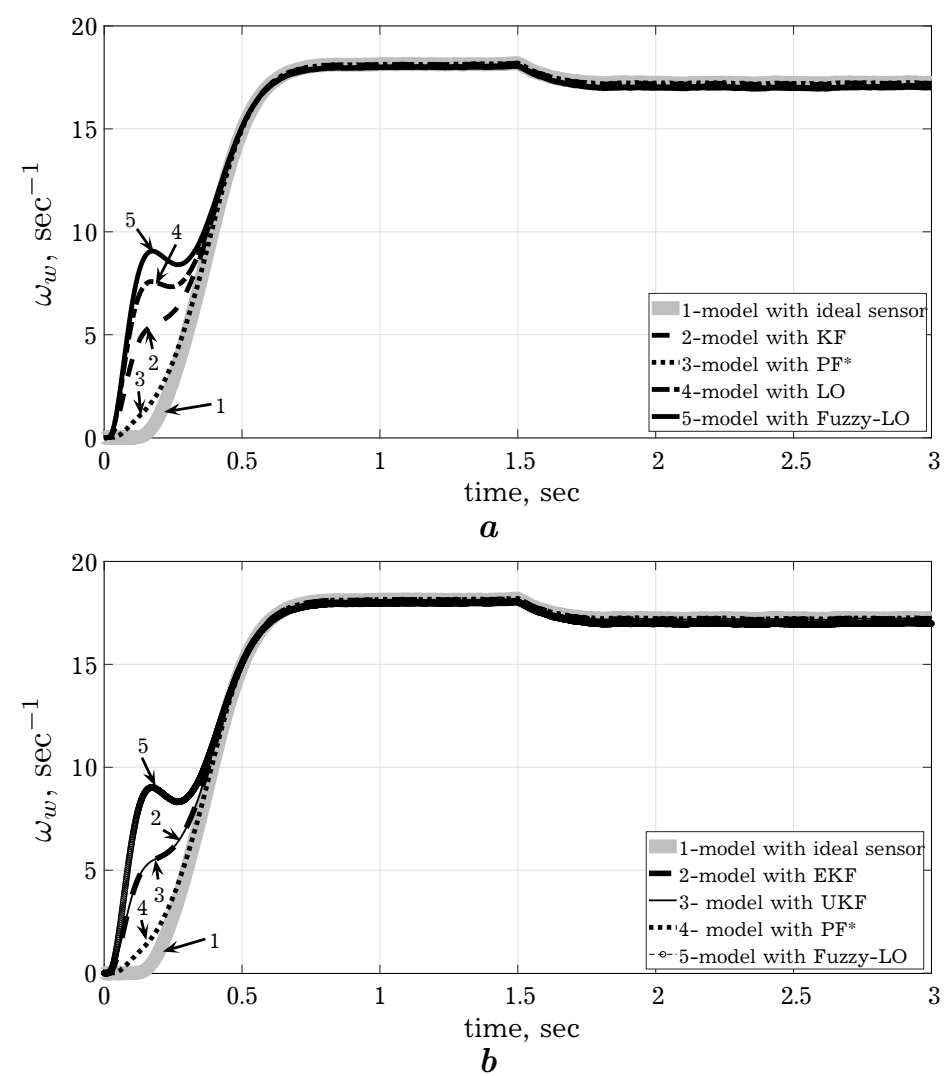

Fig. 13. System output (the wheel velocity) provided by different observers for $(\boldsymbol{a})$ the linear model and $(\boldsymbol{b})$ the non-linear model. 


\section{Conclusions}

It is often difficult to determine at which point of state space a dynamic system is located, especially if the system is characterized by fast dynamics. In this case, the incorrect initial conditions cause the incorrect real-time modeling of physical objects by using the math model. In particular, this relates to the model-based state observers that are sensitive to inaccurate initial conditions. Therefore, the studies conducted in this article provide guidance for choosing the method of state observer with the highest convergence rate.

The observers designed for the linear and nonlinear models of the locomotion module were simulated and compared when the initial state values were assigned different to the actual values. The best convergence results were obtained for the $\mathrm{PF}^{*}$ when the observer was applied for either the linear and nonlinear models of the module under different values of the divergence between the real and presumed initial conditions. For divergence of $100 \%$, the $\mathrm{PF}^{*}$ is faster than $\mathrm{KF}$ by $0.0120 \mathrm{sec}$, faster than EKF by $0.0120 \mathrm{sec}$, faster than UKF by $0.0120 \mathrm{sec}$, faster than LO by $0.0290 \mathrm{sec}$ and faster the fuzzy-LO by 0.0240 sec. The KF, EKF, UKF have demonstrated a slower convergence than the $\mathrm{PF}^{*}$ but they have faster convergence than the LO and the fuzzy-LO. The fuzzy-LO with the given degrees of freedom of the fuzzy switcher converges faster than the LO, however, it has a more complex tuning procedure and leads to a worse dynamics of the controlled output than the output achieved with the use of the other observers.

[1] Lopez-Ramirez F., Polyakov A., Efimov D., Perruquetti W. Finite-time and fixed-time observer design: Implicit Lyapunov function approach. Automatica. 87, 52-60 (2018).

[2] Huangfu Y., Xu J., Zhao D., Liu Y., Gao F. A Novel Battery State of Charge Estimation Method Based on a Super-Twisting Sliding Mode Observer. Energies. 11 (5), 1-21 (2018).

[3] Guo B.Z., Zhao Z. L. On the convergence of an extended state observer for nonlinear systems with uncertainty. Systems \& Control Letters. 60 (6), 420-430 (2011).

[4] Hong J., Laflamme S., Dodson J., Joyce B. Introduction to state estimation of high-rate system dynamics. Sensors. 18 (1), 217 (2018).

[5] BogdanskiK., Best M. C. Kalman and particle filtering methods for full vehicle and tyre identification. Vehicle System Dynamics. 56 (5), 769-790 (2018).

[6] Kalman R.E. A new approach to linear filtering and prediction problems. Journal of basic Engineering. 82 (1), 35-45 (1960).

[7] Luenberger D. G. Observing the state of a linear system. IEEE transactions on military electronics. 8 (2), 74-80 (1964).

[8] Gordon N. J., Salmond D. J., Smith A. F. Novel approach to nonlinear/non-Gaussian Bayesian state estimation. IEE Proceedings F - radar and signal processing. 140 (2), 107-113 (1993).

[9] Julier S. J., Uhlmann J. K., Durrant-Whyte H. F. A new approach for filtering nonlinear systems. Proceedings of 1995 American Control Conference - ACC'95. 3, 1628-1632 (1995).

[10] Vantsevich V. V., Lozynskyy A., Demkiv L. A Wheel Rotational Velocity Control Strategy for An open-Link Locomotion Module. Article \#171, 19th International and 14th European-African Regional Conference of the ISTVS. 25-27 (2017).

[11] Vantsevich V., Gorsich D., Lozynskyy A., Demkiv L., Borovets T. State observers: an overview and application to agile tire slippage dynamics. Proceeding of 10th Asia-Pacific Conference of ISTVS. 1-18 (2018).

[12] Buechner S., Schreiber V., Amthor A., Ament C., Eichhorn M. Nonlinear modeling and identification of a dc-motor with friction and cogging. IECON 2013 - 39th Annual Conference of the IEEE Industrial Electronics Society. 3621-3627 (2013).

[13] Kara T., Eker I. Nonlinear modeling and identification of a DC motor for bidirectional operation with real time experiments. Energy Conversion and Management. 45 (7-8), 1087-1106 (2004).

[14] Thrun S., Burgard W., Fox D. Probabilistic robotics. MIT Press (2005). 


\title{
Точність спостерігачів координат вектора стану за неточних початкових умов
}

\author{
Лозинський А. О. ${ }^{1}$, Демків Л. І. ${ }^{1}$, Ванцевич В. В. ${ }^{2}$, Боровець Т. В. ${ }^{1}$, Горсіч Д. Д. ${ }^{3}$ \\ ${ }^{1}$ Начіональний університет "Львівсъка політехніка", \\ вул. С. Бандери, 12, Лъвів, 79013, Україна \\ 2 Університет Алабами в Бірмінгемі, США \\ ${ }^{3}$ Центр систем наземного транспорту армії США, Воррен, штат Мічиган
}

\begin{abstract}
Швидка збіжність спостерігача забезпечує можливість відстежувати стани системи для довільного розузгодження між реальними та заданими початковими умовами. Така властивість спостерігача особливо необхідна, якщо система має швидку динаміку, а її стани швидко змінюються. Отже, час збіжності є одним із головних критеріїв вибору спостерігачів як для лінійних, так і для нелінійних систем.

У цій роботі подано порівняльний аналіз спостерігачів для лінійних і нелінійних систем з погляду часу збіжності. На основі аналізу літературних джерел для цього дослідження вибрані такі спостерігачі: фільтр Калмана (KF), розширений фільтр Калмана (EKF), $\sigma$-точковий фільтр Калмана (UKF), фільтр частинок (PF), спостерігач Люенбергера (LO) та нечіткий спостерігач Люенбергера (Fuzzy-LO). Перелічених спостерігачів досліджували на нелінійній математичній моделі модуля руху, який описує рух однієї четвертої частини електромобіля в умовах стохастичного рельєфу. 3 метою оцінки ефективності лінійних спостерігачів математичну модель спростили до лінійної, нехтуючи усіма нелінійностями. Математичним моделюванням було встановлено, що Fuzzy-LO з адаптивним налаштуванням коефіцієнтів матриці спостерігача дає кращі результати, ніж традиційний LO, особливо в усталених режимах. PF з початковим гауссівським розподілом точок простору стану системи забезпечує повільнішу швидкодію спостерігача, ніж KF, EKF та UKF. 3 метою підвищення швидкодії PF, у роботі запропоновано новий алгоритм $\mathrm{PF}^{*}$, в якому використано суміш гауссівських розподілів для початкової генерації точок. Покращений алгоритм фільтра частинок PF* забезпечив найшвидшу динаміку збіжності оцінених станів динамічної системи до значень станів реальної системи порівняно із роглянутими спостерігачами.
\end{abstract}

Ключові слова: алгоритми оцінки, спостерігачі простору станів, модель в системі простору станів, нечітка логіка, суміш розподілів.

2000 MSC: $93 \mathrm{~B} 07$

УдК: 681.516 .4 